\title{
Prediction of Acute Kidney Injury in Term Newborn Following Perinatal Asphyxia
}

\author{
A.S.ELsayed ${ }^{1}$, H.R.Omar ${ }^{1}$, W.A.Abd Elhalim ${ }^{2}$ and A.M.Eltokhy ${ }^{1}$ \\ ${ }^{1}$ Pediatrics Dept., Faculty of Medicine, Benha Univ., Benha, Egypt \\ ${ }^{2}$ Clinical and Chemical Pathology Dept., Faculty of Medicine, Benha Univ., Benha, Egypt \\ E-Mail:Aml2356@gmail.com
}

\begin{abstract}
Asphyxia remains a common problem in neonatal units and is a significant cause of morbidity and death in term and preterm neonates. Hypoxic Ischemic Encephalopathy (HIE) is a type of brain damage that occurs when an infant's brain doesn't receive enough oxygen and blood. It is a dangerous condition that requires immediate medical intervention. Hypoxic hurt camwood impact the greater part organs of the neonate, kidneys are really touchy will hypoxia, renal inadequacy might happen inside 24 hrs of a hypoxic insult, which whether prolonged, might prompt irreversible damage. Might have been should foresee the frequency of AKI for expression infant for Dad Furthermore on associate it for the seriousness about hidrotic. Sixty fullterm infant which would diagnosed as Dad were included, Investigations were completed In the third day of term. Serum urea and creatinine levels were measured utilizing those Bio frameworks reagent unit. Those study indicated serum urea and creatinine levels altogether expanded for propelled hidrotic phases. Neonates with propelled hidrotic stage needed fundamentally higher frequency about AKI.
\end{abstract}

Keywords Serum urea and creatinine, Perinatal asphyxia, Hypoxic ischemic encephalopathy, Acute hidney injury, Term neonate.

\section{Introduction}

The universe wellbeing association (WHO) characterizes perinatal asphyxia (PA) as "a disappointment to launch Also manage relaxing at conception." [1].

Asphyxia remains An basic issue for neonatal units and is An huge reason for horribleness and demise for expression and preterm neonates. Those occurrence for asphyxia will be assessed should a chance to be between 1 and 8 for every 1000 live births [2].

Hypoxic ischemic encephalopathy (HIE) will be a kind from claiming cerebrum harm that happens The point when an infant's mind doesn't accept sufficient oxygen and blood. The accurate timing for which may be often obscure [3]. It may be a risky state that obliges quick therapeutic intercession. Perinatal hidrotic may be connected with a $25 \%$ body of evidence fatback Throughout the beginning month about life[4].

Intense kidney harm (AKI) may be customarily characterized Likewise a unforeseen decay Previously, kidney work which reasons lopsidedness clinched alongside liquid balance, electrolytes, and waste results [5].

Hypoxic hurt could impact constantly on organs of the neonate, kidneys would altogether touchy will hypoxia, renal inadequacy could happen inside $24 \mathrm{hrs}$ of a hypoxic insult, which Assuming that prolonged, might prompt irreversible harm. AKI may be described Eventually Tom's perusing An sudden demise hindrance of renal capacity that brings about modified fluid, electrolyte, What's more corrosive base parity. It influences $8 \%-24 \%$ about critically sick neonates Also need a mortality from claiming $10 \%-61 \%$. The basic states helping on kidney damage in the neonatal period incorporate neonatal sepsis, conception asphyxia, respiratory trouble syndrome, dehydration, heart failure, Also urologic anomalies, those main two continuously those practically regular causes[6].

\section{Patients and methods Patients}

This study was performed Prospectively for (60) neonates In the third day from claiming life, which are diagnosed Similarly as Dad starting with the neonatal seriousness (NICU) from claiming Benha school Hospital,Kalyobia In a time extending starting with May, 2019 to January, 2020 after getting the required powers permissions.

Parental educated assent might have been taken former should Incorporation and the investigation might have been sanction by the nearby morals panel of Benha school.

Incorporation criteria to those ponder one assembly were full term baby ( Gestational period $\geq 37$ weeks ), 1 5 minutes Apgar $<7$, To begin with postnatal ph $<7$. 1, clinical examination What's more organizing for hidrotic.

Hidrotic phases were evaluated altogether mulled over neonates, (51. 7\%) 31 situations needed stage I, (40\%) 24 cases required stage ii and (8. 3\%) 5 cases needed phase iii.

Preterm newborn child ( Gestational agdistis < 37 weeks ), Neonates with conception trauma, Neonates with intrinsic anomalies, Neonates for suspected intrinsic slip of metabolism, Neonates for septicemia, Neonates for respiratory misery syndrome were excluded from this consider.

\section{1 Methods}

Constantly on members were subjected with finish history taking, finish clinical examination. Research center investigations:. String blood gas dissection might have been completed toward conception $(\mathrm{pH}, \mathrm{pCO} 2$, bicarbonate, build deficit). String blood specimens were gathered starting with twofold clamped umber cord, anaerobically, utilizing heparinized disposable syringes ( $2 \mathrm{ml}$ syringe washed Eventually Tom's perusing 1000IU/ 
$\mathrm{ml}$ heparin). It straightforwardly measures $\mathrm{pH}, \mathrm{pCO} 2$, bicarbonate, base deficiency.

Schedule lab tests completed toward 3st day of life were cbc might have been assessed Toward Sysmex-XP 300, (USA). Serum Creatinine might have been assessed with the Bio frameworks reagent unit furnished Toward Bio frameworks encountered with urban decay because of deindustrialization, innovation developed, government lodgin. An. (Barcelona, Spain) by altered Jaffe response. Serum urea might have been controlled Toward those enzymatic colorimetric test, utilizing An jewel kit, (Diamond Diagnostics, Holliston, USA). Liver work tests might have been assessed Toward Roponic gadget. ABG might have been assessed Eventually Tom's perusing Cobas b121, (Mannheim, Germany). Serum electrolytes ( serum sodium Furthermore potassium) were assessed Toward ST-200 Besides electrolytes analyzer (SENSA CORE).

Cranial Ultra-Sonographic examination might have been performed ahead the 3 rd day of existence. The pee for neonates might have been gathered for 24 hours for the 3rd day of an aggregation.

\section{2 Measurable analysis}

Those gathered information were tabulated and investigated utilizing SPSS rendition 16 delicate ware (SpssInc, Chicago, sick organization). Unmitigated information were introduced Likewise supreme Also relative $(\%)$ frequencies. Chi-square test ( X2), or Fisher's correct test (FET) were used to examine unmitigated variables. Quantitative information were tried to typicality utilizing Shapiro-Wilks test, accepting typicality at $\mathrm{P}>0.05$, they were communicated as imply \pm standard deviation if regularly disseminated or average What's more IQR whether not. Scholar " $t$ " test might have been used to dissect typically conveyed variables "around 2 autonomous Assemblies. Kruskal-Wallis test might have been utilized. Same time non-parametric variables were broke down utilizing mamoncillo Whitney u test. Spearman's relationship coefficient (rho) might have been used to survey liner cooperations the middle of variables. Roc bend might have been used to figure out those cutoff quality for ideal affectability What's more specificity. Relapse investigation might have been run will identify the predictors. The acknowledged level about noteworthiness in this worth of effort might have been stated In 0.05 ( $\mathrm{P}<0.05$ might have been viewed as significant) [7].

\section{Results}

The present study included a total of (60) full term newborn at the third day of life, which were diagnosed as PA. All of them were full term infants (GA $\geq$ 37 weeks), mean GA was 37.7 weeks. They were 33 males $(55 \%)$ and 27 females (45\%). Mean weight was $2.8 \mathrm{~kg}$. Out of them, 15 neonates $(25 \%)$ were LBW.

Out of all studiedneonates, 24 had AKI $(40 \%)$. Table (1) and Fig (1).

HIE advanced stages were significantly associated with AKI ( $\mathrm{p}<0.001)$ Table (2) and Fig (2)

Advanced HIE stages were significantly associated with AKI ( $p<0.001)$ Table (3)

Higher ALT, AST, creatinine and urea concentrations were significantly associated with AKI $(\mathrm{p}=0.01,0.032$, $0.014,<0.001$ respectively). Otherwise, no significant differences were found in laboratory data of between studied neonates with and without AKI Table (4).

Lower UOP was significantly associated with AKI when compared to those without AKI $(\mathrm{p}<0.001)$ Table (5).

Regression analysis was conducted for prediction of AKI within PA neonates using gender, GA, weight, Na, $\mathrm{K}$, HIE stages as covariates.Advanced HIE stages was associated with risk of AKI occurrence within PA neonates Table (6).

Table (1) AKI in all studied neonates.

\begin{tabular}{lllll}
\hline & & & \multicolumn{3}{c}{ PA N=60 } \\
\hline AKI & Absent & N, \% & 36 & $60 \%$ \\
& Present & N, \% & 24 & $40 \%$ \\
\hline
\end{tabular}

$\mathrm{AKI}=$ Acute kidney injury $\quad \mathrm{PA}=$ Perinatal asphyxia

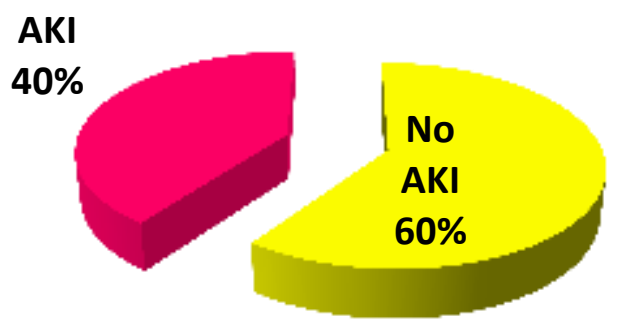

Fig (1) AKI in all studied neonates. 
Table (2) Comparison of AKI of between studied neonates according to HIE stages.

\begin{tabular}{lllccccccc}
\hline & & & \multicolumn{2}{c}{ I N=31 } & \multicolumn{1}{c}{ II N=24 } & \multicolumn{2}{c}{ III N=5 } & P \\
\hline \multirow{2}{*}{ AKI } & Absent & $\mathbf{N}, \%$ & 31 & $100 \%$ & 5 & $20.8 \%$ & 0 & $0 \%$ & $<0.001$ \\
& Present & $\mathrm{N}, \%$ & 0 & $0 \%$ & 19 & $79.2 \%$ & 5 & $100 \%$ & \\
\hline
\end{tabular}

HIE $=$ Hypoxic ischemic encephalopathy $\quad$ AKI = Acute kidney injury

AKI Absent $\quad$ AKI Present

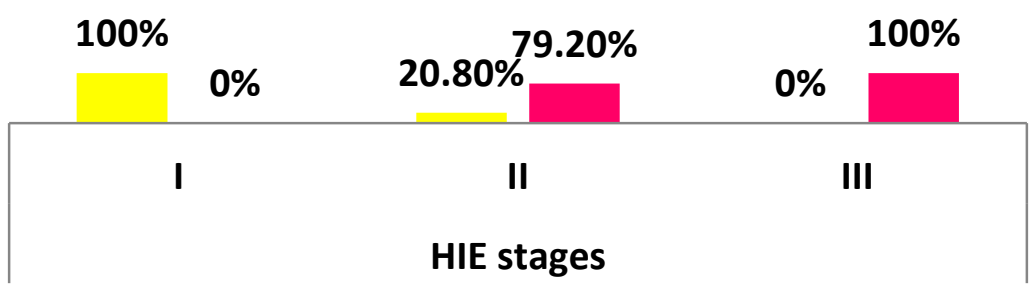

Fig (2) AKI in studied neonates according to HIE stages.

Table (3) Comparison of HIE stages of between studied neonates with and without AKI.

\begin{tabular}{lllccccc}
\hline & & \multicolumn{1}{c}{ No AKI $\mathbf{N}=\mathbf{3 6}$} & AKI $\mathbf{N}=\mathbf{2 4}$ & $\mathbf{P}$ \\
\hline HIE stages & I & N, \% & 31 & $86.1 \%$ & 0 & $0 \%$ & $<0.001$ \\
& II & N, \% & 5 & $13.9 \%$ & 19 & $79.2 \%$ & \\
& III & N, \% & 0 & $0 \%$ & 5 & $20.8 \%$ & \\
\hline
\end{tabular}

$$
\mathrm{AKI}=\text { Acute kidney injury } \quad \mathrm{HIE}=\text { Hypoxic ischemic encephalopathy }
$$

Table (4) Comparison of laboratory data of between studied neonates with and without AKI.

\begin{tabular}{|c|c|c|c|c|c|c|}
\hline & & \multicolumn{2}{|c|}{ No AKI $N=36$} & \multicolumn{2}{|c|}{ AKI $\mathrm{N}=\mathbf{2 4}$} & \multirow{2}{*}{$\begin{array}{c}\mathbf{P} \\
0.338\end{array}$} \\
\hline $\begin{array}{l}\text { Hemoglobin } \\
\text { (g/dL) }\end{array}$ & mean \pm SD & 14.0 & 2.4 & 14.6 & 2.5 & \\
\hline HCT (\%) & mean $\pm \mathrm{SD}$ & 41.8 & 7.8 & 43.9 & 7.1 & 0.289 \\
\hline TLC $\left(\mathbf{X 1 0}^{9}\right)$ & mean \pm SD & 12.6 & 3.4 & 13.0 & 4.0 & 0.792 \\
\hline Platelets $\left(\mathrm{X}^{10}{ }^{9}\right)$ & mean $\pm \mathrm{SD}$ & 211.9 & 65.5 & 216.0 & 71.4 & 0.820 \\
\hline $\operatorname{ALT}(\mathbf{U} / \mathbf{L})$ & mean $\pm \mathrm{SD}$ & 23.1 & 7.7 & 28.4 & 7.4 & 0.010 \\
\hline $\operatorname{AST}(\mathbf{U} / \mathbf{L})$ & mean $\pm \mathrm{SD}$ & 36.8 & 10.5 & 49.3 & 13.1 & 0.032 \\
\hline Urea (mg/dL) & mean $\pm \mathrm{SD}$ & 26.5 & 6.7 & 38.6 & 12.4 & 0.014 \\
\hline $\begin{array}{l}\text { Creatinine } \\
(\mathrm{mg} / \mathrm{dL})\end{array}$ & mean $\pm \mathrm{SD}$ & 0.6 & 0.2 & 1.7 & 0.5 & $<0.001$ \\
\hline $\mathbf{N a}$ & mean $\pm \mathrm{SD}$ & 137.3 & 4.3 & 136.7 & 7.8 & 0.717 \\
\hline $\mathbf{K}$ & mean $\pm \mathrm{SD}$ & 4.2 & 0.8 & 4.5 & 0.8 & 0.247 \\
\hline PH & mean $\pm \mathrm{SD}$ & 7.3 & 0.1 & 7.2 & 0.1 & 0.080 \\
\hline $\mathrm{CO}_{2}$ & mean $\pm \mathrm{SD}$ & 40.9 & 12 & 41.1 & 13 & 0.958 \\
\hline $\mathrm{HCO}_{3}$ & mean $\pm \mathrm{SD}$ & 20.9 & 6.5 & 19.1 & 4 & 0.365 \\
\hline
\end{tabular}

$\mathrm{AKI}=$ Acute kidney injury $\quad \mathrm{HCT}=$ Hematocrite $\quad$ TLC $=$ Total leucocytic count

ALT $=$ Alanine aminotransferase $\quad$ AST $=$ Aspartate Transaminase $\quad \mathrm{Na}=$ Sodium $\mathrm{K}=$ Potassium $\quad \mathrm{PH}=$ Power of oxygen $\quad \mathrm{CO} 2=$ Carbon dioxide $\quad \mathrm{HCO} 3=$ Bicarbonates $\mathrm{SD}=$ standard deviation

Table (5) Comparison of laboratory data of between studied neonates with and without AKI.

\begin{tabular}{|c|c|c|c|c|c|c|}
\hline & & & $\mathrm{N}=36$ & & $\mathrm{~N}=24$ & $\mathbf{P}$ \\
\hline UOP (cc/kg/h) & mean \pm SD & 2.5 & 0.5 & 1.2 & 0.3 & $<0.001$ \\
\hline
\end{tabular}

$\mathrm{UOP}=$ Urine output $\quad \mathrm{AKI}=$ Acute kidney injury $\quad \mathrm{SD}=$ standard deviation 
Table (6) Regression analysis for prediction of AKI within PA neonates.

\begin{tabular}{lcccc}
\hline & P & OR & \multicolumn{2}{c}{$\mathbf{9 5 \%}$ CI } \\
\hline Gender & 0.138 & 0.608 & 0.315 & 1.173 \\
GA & 0.574 & 0.896 & 0.611 & 1.314 \\
LBW & 1.000 & 1.000 & 0.477 & 2.098 \\
Na & 0.718 & 0.990 & 0.938 & 1.045 \\
K & 0.242 & 1.287 & 0.844 & 1.963 \\
HIE & $<0.001$ & 3.772 & 2.126 & 6.693 \\
\hline
\end{tabular}

$$
\begin{aligned}
& \mathrm{OR}=\text { odds ratio } \quad \mathrm{CI}=\text { confidence interval. } \quad \mathrm{AKI}=\text { Acute kidney injury } \\
& \mathrm{PA}=\text { Perinatal asphyxia } \quad \mathrm{GA}=\text { Gestational age } \quad \mathrm{LBW}=\text { Low birth weight } \\
& \mathrm{Na}=\text { Sodium } \mathrm{K}=\text { Potasioum } \quad \mathrm{HIE}=\text { Hypoxic ischemic encephalopathy }
\end{aligned}
$$

\section{Disscusion}

The vicinity from claiming perinatal asphyxia Also its seriousness show up should associate with expanding occurrence for AKI. Asphyxia is a paramount reason for AKI What's more transient kidney impedance for unfriendly effects, particularly in the five days from claiming conception. Those kidney may be the The majority harmed organ Previously, suffocated full- haul babies [8].

Done present study, higher ALT, AST, creatinine Furthermore urea focuses were essentially connected with AKI ( $\mathrm{p}=0.01,0.032,0.014,<0.001$ respectively). Otherwise, no huge contrasts were found Previously, research center information of between concentrated on neonates for Furthermore without AKI .

This suitably for [6] whoreported that "around AKI might have been diagnosed On 42 newborns (44. 21\%) that were incorporated Previously, assembly i (AKI group) and the remaining done bunch ii (non-AKI group). Those neonates in the two aggregations needed a noteworthy distinction On beginning blood urea and creatinine values toward those duration of the time from claiming confirmation .

Comparable outcomes Eventually Tom's perusing [9] Similarly as they discovered critical contrasts in the levels about urea and creatinine were watched done suffocated neonates for AKI as contrasted with suffocated neonates without AKI $(\mathrm{p}<0.001$.)

Also, "around 90 neonates, 75 cases and 50 controls were decided over study Toward [10] the blood urea Furthermore serum creatinine levels were higher clinched alongside cases with renal debilitation over controls $(\mathrm{P}=0$. 001). By there might have been no refinement over electrolyte levels clinched alongside both .

This disagreed with Bhatnagar, Bairwa What's more Meena [11] who discovered that there were no noteworthy contrasts $\mathrm{On}$ levels of $\mathrm{sCr}$ the middle of the AKI and non-AKI Assemblies .

To present study, hypoxic ischemic encephalopathy (HIE) phases were evaluated altogether contemplated neonates, $51.7 \%$ needed phase I, $40 \%$ required stage ii What's more $8.3 \%$ required phase iii. Hidrotic propelled phases were essentially connected with AKI $(\mathrm{p}<0.001)$ Likewise it influenced 0\%, 79. 2\% \&100\% done review I, II\&III respectively). This concurred for [12] who accounted for that those frequency of AKI altogether associated with seriousness about hidrotic stage Similarly as AKI might have been watched clinched alongside 14 out of the 36 reasonably suffocated babies and all 14 babies for extreme asphyxia. None of the babies in the control assembly required AKI .

Also, as stated by investigation Eventually Tom's perusing [9] the level of perinatal asphyxia might have been arranged utilizing Sarnat What's more Sarnat organizing about Hypoxic ischaemic encephalopathy (HIE) around confirmation. Dominant part 31(52\%) needed hidrotic II, $22(36 \%)$ hidrotic i Also 7 (12\%) hidrotic iii .

This disagreed for [13] who required two thirds for newborns with AKI needed review ii What's more $1 / 3$ for AKI needed evaluation iii. In any case for as much contemplate no renal hindrance might have been watched done newborns for review i. Those distinction might have been not statistically noteworthy $(\mathrm{p}=0.13)$.

On current study, ALT, AST, urea Furthermore creatinine focuses expanded essentially with propelled hidrotic phases $\mathrm{P}=0$. 002, 0. 009, <0. $001 \&<0.001$ respectively). On the other hands, finish blood picture (CBC), electrolytes Also blood gasses didn't vary essentially the middle of hidrotic phases. This might be demonstrated on the premise about actuation of the 'diving reflex' in the pathophysiology about asphyxia [8].

his suitably for Shrikhande, Singh What's more Garg [8] who news person that those The majority normal presentation of renal association in the display ponder might have been found will be in the structure for a raised serum creatinine (64\%) taken after Toward raised urea $(17 \%)$. In display ponder raised serum creatinine might have been display done 69 (45\%) suffocated neonates .

Also, El-Gamasy Also Alarabawy [14] indicated examination about serum creatinine level On examined tolerant subgroups as stated by Sarnat What's more Sarnat arranging. This table demonstrated that method for serum creatinine were essentially expanded with those expansion clinched alongside seriousness for hidrotic as stated by Sarnat and Sarnat arranging .

What's more "around downright for 85 suffocated neonates were incorporated On Medani, Kheir and Mohamed [15] study. Serum creatinine might have been 
going the middle of 1. 5-1. 9mg/ dl Previously, 10 (21. $74 \%$ ) babies, 2-3mg/dl Previously, 29 (63. 04\%) Also more than $3 \mathrm{mg} / \mathrm{dl}$ to 7 (15. 22\%) neonates for noteworthy Acquaintanceship for hidrotic organizing ( $\mathrm{p}$ value $=0.003$

Also, [16] clinched alongside as much ponder watched that $56 \%$ for suffocated babies needed brought up creatinine .

Also, this suitably with [17] who news person tha blood urea Also serum creatinine were fundamentally higher for suffocated babies contrasted with control aggregation $(\mathrm{P}<0$. 001) Furthermore $(\mathrm{P}<0$. 05) individually Subsequently demonstrating to the relationship between AKI and hidrotic. An climbing pattern done centralization for blood urea Furthermore creatinine might have been watched as hidrotic organizing of neonates advanced and the Contrast might have been statistically critical between babies with no hidrotic What's more the individuals with hidrotic stage III, $(\mathrm{P}<0.05)$.

Also, this concurred with Hankins What's more speer [18] who discovered brought up creatinine clinched alongside $61 \%$ of babies for asphyxia .

Also, [19] found that, outcomes about complete blood check (regarding $\mathrm{Hb} \%$, platelets, and white platelet counts) were not altogether separate between instances and controls ( $\mathrm{P}>0$ 05). Blood urea Also Scr levels needed been raised essentially for suffocated cases $(\mathrm{P}<0.001)$.

Also, this might have been in line with whofound that the serum parameters similar to urea Also creatinine demonstrated critical distinction the middle of suffocated instances Furthermore controls .

This disagreed with [6] who accounted for thatthe values for urea and creatinine were bring down Previously, suffocated neonates with AKI, the distinction being statistically huge $(\mathrm{P}<0.05)$. This signifies that a starting typical blood urea/serum creatinine esteem can't discount AKI Also underlines those imperative for serial observing .

This disagreed with [20] who accounted for that, those blood urea Also creatinine might have been raised "around situations What's more higher levels about both qualities discovered for seriousness for asphyxia. Those intend blood urea levels indicated no critical distinction Around bunches for seriousness for asphyxia. Be that as however those serum creatinine esteem might have been higher over cases for extreme asphyxia, the distinction "around the Assemblies might have been not statistically noteworthy .

Also, this disagreed with Bhatnagar, Bairwa Also Meena [11] who accounted thatthere might have been no critical distinction As far as $\mathrm{sCr}$ "around those control group, moderate asphyxia group, and extreme asphyxia aggregation $24 \mathrm{~h}$ then afterward conception ( $\mathrm{p}>0.05)$.

In present study, propelled hidrotic phases were essentially connected with AKI ( $\mathrm{p}<0.001)$.

This might have been Previously, concur with [9] who found that, AKI might have been most noteworthy in the neonates with hidrotic iii (42.9\%) around day 3 of term Also least in the neonates for hidrotic 1 (4. 6\%). [9] investigation noted a 15 fold build hazard for Creating AKI Previously, hidrotic iii contrasted with hidrotic I, $\mathrm{p}=0.034$.

Also, a number investigations uncovered that, the vicinity about perinatal asphyxia Furthermore its seriousness seems should associate for expanding frequency for AKI [17,21].

Also, A large number investigations uncovered that's only the tip of the iceberg extremely suffocated neonates need aid less averse with experience AKI over the individuals for milder asphyxia. AKI might have been noted in 14 out of the 36 (39\%) reasonably suffocated babies and $14(100 \%)$ babies for extreme asphyxia $[16,17,22,23]$.

In line for current results, [24] who accounted for that AKI formed for 1 crazy for 11 babies (9. 1\%) with moderate asphyxia Also for 12 about 25 (56\%) for extreme asphyxia .

Additionally this suitably wirh Karlowicz Also Adelman [25] who accounted that AKI struck them On $61 \%$ about babies with extreme asphyxia compared with $0 \%$ On the individuals with moderate asphyxia .

This disagreed with Bhatnagar, Bairwa Also Meena [11] who news person that the predominance about AKI might have been not essentially distinctive the middle of Different phases for hidrotic .

Also, this disagreed for [13] who news person that two thirds about newborns with AKI required evaluation ii Furthermore 1/3 for AKI needed review iii .

Over current study, relapse investigation might have been directed to prediction of AKI inside Dad neonates utilizing gender, GA, weight, $\mathrm{Na}$, K, hidrotic phases Similarly as covariates. Propelled hidrotic phases might have been altogether connected with danger from claiming AKI event inside Dad neonates $(\mathrm{p}<0$. 001).

Comparative finding done study Eventually Tom's perusing [6] Univariate dissection from claiming variables for example, gender, imply conception weight, intend gestational age, toward conception didn't uncover any huge prediction about AKI .

Different investigations help the relationship from claiming AKI frequency for propelling seriousness from claiming hypoxic ischemic encephalopathy $[26,9]$.

Also, this suitably for [24] whoreported that there might have been huge part of asphyxia level for prediction from claiming AKI. AKI frequency of $41.7 \%$ On suffocated neonates, with an frequency about $9.1 \%$ Previously, babies for direct asphyxia What's more 56\% "around babies for extreme asphyxia .

\section{Determination}

Perinatal asphyxia will be a paramount reason for neonatal AKI. Screening for blood levels for urea, serum creatinine, and pee yield serves in the punctual analysis What's more management from claiming AKI over conception asphyxia .

However, for conception asphyxia, since non oliguric $\mathrm{AKI}$ is common, observing best pee yield doesn't help in 
the analysis for intense kidney injury, the biochemical parameters On blood if be monitored .

Neonates with propelled hidrotic phase needed essentially higher frequency from claiming AKI .

Higher creatinine, urea, low UOP were essentially connected with propelled hidrotic phases Previously, Dad neonates.

\section{Referances}

[1] P. Malhotra, K. Syal , A. Singh, et al., Acute Kidney Injury in Perinatal Asphyxia: Comparison Between Term and Preterm Neonates. Journal of Neonatology, Vol.32(2-3), PP.50-59, 2018.

[2] A. Medani , E. Kheir , B. Mohamed, Acute kidney injury in asphyxiated neonates admitted to a tertiary neonatal unit in Sudan. Sudanese journal of paediatrics, Vol.14(2), PP.29, 2014.

[3] S. Zanelli , Hypoxic ischaemic encephalopathy. Available from : http : // emedicine . medscape .com/article/973501-overview, Accessed date, Vol.6, pp.240-244, 2016.

[4] G. Natarajan, A. Mathur, I. Zaniletti, Withdrawal of Life-Support in Neonatal HypoxicIschemic Encephalopathy. Pediatric neurology, Vol.91, pp.20-26, 2019.

[5] A. Bakhsh, Acute kidney injury in term neonates withperinatal asphyxia: a literature review. European Journal of Basic and Clinical Medical Sciences, Vol.1(1), pp.35-42, 2018.

[6] M. Aslam, S. Arya, H. Chellani, et al., Incidence and predictors of acute kidney injury in birth asphyxia in a Tertiary Care Hospital. Journal of Clinical Neonatology, Vol.6, PP.240-244, 2017.

[7] H. Himmerich, A.J. Sheldrick, TNF- $\alpha$ and ghrelin: opposite effects on immune system, metabolism and mental health. Protein and peptide letters, Vol.17(2), pp.186-96, 2010.

[8] D. Shrikhande, V. Singh, A. Garg, Study of renal functions in neonatal asphyxia. Pravara Medical Review, Vol.6, PP.240-244. 2016.

[9] D. Alaro, A. Bashir, R. Musoke, Prevalence and outcomes of acute kidney injury in term neonates with perinatal asphyxia. African health sciences, Vol.14, PP.682-688, 2014.

[10] S.Reddy, N.Reddy, J.Nagasravani, et al., Incidence of Acute Renal Failure in Birth Asphyxia and its Correlation with Hypoxic Ischemic Encephalopathy (HIE):. International Journal of Medical Research \& Health Sciences, Vol.6, PP.80-91, 2017.

[11] A.Bhatnagar, A.Bairwa , K .Meena, Incidence of acute kidney injury in perinatal asphyxia and its correlation with hypoxic ischemic encephalopathy (HIE): staging. PARIPEX-Indian Journal ofResearch, Vol, 3, PP.12-13, 2014.

[12] J.Karlo, B.Bhat, B.Koner, et al., Evaluation of Renal Function in Term Babies with Perinatal Asphyxia. Indian journal of pediatrics, Vol.10, PP.125-160, 2014
[13] S. Nouri, N. Mahdhaoui, S.Beizig, et al., [Acute renal failure in full term neonates with perinatal asphyxia. Prospective study of 87 cases]. Archives de pediatrie: organe officiel de la Societe francaise de pediatrie, Vol.15, PP.229235, 2008.

[14] A.El-Gamasy , R.Alarabawy Relation of Serum Creatinine to Sarnat Scoring and Brain Computerized Tomography of Neonates with Hypoxic Ischemic Encephalopathy. A SingleCenter Experience. J Pediatr Neurosci, Vol.13, PP.437-442, 2018.

[15] A. Medani , E. Kheir , B. Mohamed ,Acute kidney injury in asphyxiated neonates admitted to a tertiary neonatal unit in Sudan. Sudanese journal of paediatrics, Vol.14(2), PP.29, 2014.

[16] A. Aggarwal , P. Kumar , G. Chowdhary , et al., Evaluation of renal functions in asphyxiated newborns. Journal of tropical pediatrics, Vol.51(5), PP.295-299, 2005.

[17] B. Gupta, P. Sharma, J. Bagla, et al., Renal failure in asphyxiated neonates. Indian pediatrics, Vol.42, PP.928, 2005.

[18] D. Hankins , M .Speer, Defining the pathogenesis and pathophysiology of neonatal encephalopathy and cerebral palsy. Obstetrics \& Gynecology, Vol.102, PP.628-636, 2003.

[19] M. El-Gendy , K. Abd El-mo'men, S. Badr, et al., $\alpha 2$-Microglobulin predicts renal injury in asphyxiated neonates. Menoufia Medical Journal, Vol.27(2), pp.316, 2014.

[20] V. Ahire, V. Patil, D. Patel, et al., A Comparative Study of Renal Parameters and Serum Calcium Levels in Birth Asphyxiated Neonates and Normal Neonates. MVP Journal of Medical Science, Vol.4, PP.97-101, 2017.

[21] A. Martín-Ancel, A. García-Alix, F. Cabañas, et al., Multiple organ involvement in perinatal asphyxia. The Journal of pediatrics, Vol.127, PP.786-793, 1995.

[22] J. Askenazi, N. Ambalavanan, L. Goldstein, Acute kidney injury in critically ill newborns: what do we know? What do we need to learn? Pediatric Nephrology, Vol.24, PP.265, 2009.

[23] V. Aldana, M. Romaro, O. Vargas, et al., Acute complications in full term neonates with severe neonatal asphyxia. Ginecologia y obstetricia de Mexico, Vol.63, PP.123-127, 1995.

[24] S. Kaur, S. Jain, A. Saha, et al., Evaluation of glomerular and tubular renal function in neonates with birth asphyxia. Annals of tropical paediatrics, Vol . 31, PP.129-134, 2011.

[25] G. Karlowicz ,D. Adelman., Nonoliguric and oliguric acute renal failure in asphyxiated term neonates. Pediatric Nephrology , Vol.9, PP.718$722,1995$.

[26] G. Gopal, Acute Kidney Injury (AKI): in perinatal asphyxia. Indian Journal of Pharmaceutical and Biological Research, Vol.2, PP.60, 2014. 